\title{
Interview
}

\section{Online news and DAM - An interview with Keith DeWeese, Tribune Interactive}

\section{Keith DeWeese}

specializes in developing controlled vocabularies and logic bases used for automated content indexing. His work supports various Tribune Company Interactive products including the Tribune Topic Galleries (http://chicagotribune.com/topic/). Before working with the Tribune Company, he was employed by Dow-Jones, the Federal Reserve and Encyclopaedia Britannica. In another life, he was an academic librarian at Columbia College-Chicago, philosophy and sociology instructor, and college administrator.

ABSTRACT This interview covers various topics related to automated indexing of interactive news content, including the cultural implications of transitioning from newspapers to online news; the impact of declining newspaper readership; applying natural language processing techniques to massive, constantly changing content sets; and the challenges of indexing content of widely varying lengths using frequency-based relevancy.

Journal of Digital Asset Management (2010) 6, 109-123. doi:10.1057/dam.2010.6

Keywords: natural language processing; knowledge management; automated indexing; controlled vocabularies; web 3.0 ; interactive news

MM: Keith DeWeese, if you would give us a little bit of your kind of current role and a little bit of your personal background.

KDW: Certainly and thank you Michael. I work for the Tribune Interactive division of Tribune Company and I have been engaged in its 'taxonomy project', managing the automated taxonomy system that we began developing in 2007 , and rolled out in early 2008. I came to the Tribune from Dow Jones-Factiva where I was a consultant working with the taxonomy, 'intelligent indexing' and solutions architecture teams. Prior to that, I was with the Federal Reserve System and worked with their internal metadata application systems. This was my first exposure to XBRL; of course, the Federal Reserve System has to be very much aware of business reporting. Before my work at the Federal Reserve, I was at Encyclopedia my mind. Before Britannica, I was engaged, for about 8 years, by Columbia College, Chicago, as an academic administrator, librarian and teacher teaching in liberal arts, all of which was preparing me for a certain career trajectory. Still, the real turning point was the indexing world of the encyclopedia.

MM: Great. How about if you give us an overview of the Tribune Company and the particular area in which you now work at Tribune Interactive?

KDW: The Tribune Company is made up of a number of divisions and markets producing numerous products and I work in the central portion of the company here in Chicago. I work very closely with product and IT, developing an automated indexing system indexing Tribune and third-party content, and the results are presented on the websites of the Baltimore Sun, Chicago Tribune, Daily Press, Hartford Courant, Morning Call, Orlando Sentinel and Sun Sentinel. Broadcast sites are also using the system we're developing, and, likewise, singular products such as the Tribune's 
HealthKey. Of course, we've gone through a great deal of change at the Tribune, and we're always rethinking our approach to supporting so many different initiatives providing us with many great, new challenges, good opportunities to rethink everything everywhere. So Chicago is at the center of this whole operation but it doesn't stand without the Markets and products. Also, there are different levels of metadata application projects working throughout the system and toward different goals. We have a huge amount of content coming in from all directions and with its own metadata, so it's a heady experience keeping all working together and for the Tribune. After a while you learn to carve out or scope your metadata domain, the area of what you can influence or control.

MM: What does Tribune Interactive do within this larger Tribune Company.

KDW: Tribune Interactive operates and develops the dynamic, online presence of local and national Tribune news. For example, when you go to http://chicagotribune.com, you're interacting with Tribune Interactive product. Of course, it does not begin and end just with Tribune Interactive, because we collaborate so much with the Tribune's incredible editorial and production teams, and we collaborate with third parties; but, ultimately, Tribune Interactive is the bridge between the Tribune's content and the end user's interactive experience with it.

MM: So that we can put this in the framework, Tribune Interactive consists of not just one site, but many different websites.

KDW: Yes, correct. Every market, let's say the Orlando Sentinel, for example, in Florida, has its own website. Again, Tribune Interactive is the bridge working with the Sentinel, their staff, their editors and producers, to serve up the content of various news agencies, our own Markets, other internal content providers and so on.

MM: As a point of reference, what web content management system do you use to manage Tribune Interactive?

KDW: We have our own proprietary Content Management System (CMS) developed over the last decade. We're always pushing it, testing it and, luckily, it's flexible allowing for a certain amount of augmentation. Other content management approaches are under review, too, to extend its functionality.
MM: You know this gets to a really interesting point that will develop as a theme in our interview today and for companies that create digital assets and publish or distribute content as primary sources of revenues: magazines, newspapers, TV program and so on. There is always a temptation to say well gee this is so core to our business, why would we want to rely on commercial software, commercial infrastructure to manage something that is so core and potentiality proprietary, and it seems to me from various conversations that I have had with executives over the years that there really is, if you will, an epic battle or trade-off between go-your-own, build proprietary technology versus let us just take commercial off-the-shelf technology and really focus on customizing that and putting more and more of our resources into content and other kinds of services that are not necessarily pure technology.

KDW: Right.

MM: Expand on that a little bit.

KDW: Well, when I look at the Tribune's CMS environment, I see a system designed to support a certain set of business requirements at a particular time though, knowing that the landscape in which we're working changes very quickly, with a certain insight into potential requirements of a future time. Not to sound myopic, but, referring to what I said earlier, I also see the CMS via the scope of what I can influence or control to a certain degree. To speak in terms of 'epics', and I know the analogy takes in a monstrosity, but, from my perspective, it's a bit like being charged with feeding one head of the Chimera or Hydra, and making sure that activity stays in balance with the rest of the creature, the system. Not to sound arrogant, but the Tribune is an epic company with an epic presence built by some epic people, the latest being Sam Zell and his revolutionary team. When you're talking in terms of epics and revolutionaries, 'off the shelf' products and services just doesn't always cut it. Epics and revolutions don't wait for third-party help desks to file tickets, and they can't tolerate, 'We'll get back to you in a couple of weeks'. There has to be a different approach. Certainly the epic vision collaborates with the providers of products and services, but it can't be slavish to them. The Tribune has a huge vision. 
Sometimes, the ultimate vision has to go through the challenging, frequently painful exercise of allowing blind men the opportunity to touch and describe the elephant with different and conflicting ideas of what they're touching, but that's a given in day-to-day experience here at the Tribune. It is not unexpected. We know that this is part of what makes this work, is a part of 'work' in general.

Now, all that said - and it's easy for me to say - but much, perhaps too much, struggle arises, in far too many corporate environments, from the pain of becoming aware of or learning the limitations of 'off the shelf' or 'out of the box' 'solutions' - and there are no real 'solutions' to anything in this world, as much as some would have us think. That pain is then exacerbated by an inability to take responsibility for developing products beyond their 'off the shelf state. Many corporations just can't do that. They weren't listening when they set up their license, and they don't have the internal resources to take the product to the nth-degree. There's an old folk tale, I think it's called 'The Three Sillies', about three dolts who won't go in their cellar because an axe is stuck in a cellar beam. All the dolts do is cry and complain about how they can't go down in the cellar to get what they need because the axe is hanging there. Ultimately, someone bright comes along and removes the axe. I think that's a lot of what happens in corporations with 'off the shelf': the license is purchased in the context of (hopefully) fully knowing the limitations of the product or service, especially when getting what you pay for. Then, rather than doing what is necessary, responsible, accountable to make the product do the utmost - while making sure that it remains in scope of what it was designed to do and does not become a monstrosity working around or bearing the weight or the failings of other products or systems - the product is emotionally perceived as being faulty, a risk, and the emotional response is complaining, gnashing of teeth, wringing of hands, etc. Of course, innovative, experimental corporate initiatives then feel the negative strain of that, and, if the negativity continues, the corporation fails in various ways. Obviously, there is no one right answer for 'what do we do now?' There is no dogmatic 'one way' because all organizations are different in terms of business requirements, goals, management expertise, staff accountability, social cultures and so on. If you're worth your salt, you know then that an 'off the shelf' approach that might work (or fail) to a certain degree for one organization is no guarantee of success (or failure) for yours. An enterprise such as the Tribune, then, which physically spans the country and willfully, knowledgeably carves out its domain on the relatively nascent and seemingly fathomless Web, realizes the need for a balanced tending of its systems even if, it has to admit that systems are what they are regardless of what one might have initially thought they were or want them to be. It's all part of a learning process, sometimes eyeopening, sometimes painful, but all a part of a certain agreement an organization makes with technology when it engages in automation, 'intelligent' process and exploring the vastness of the Web.

MM: That is right. You know this leads nicely into a theme that I would like to further develop here. Those are some of the larger trends in publishing and specifically there are a couple of things that I would like you to comment on in any particular order. First, you know the young folks, young adults are not reading newspapers as clearly as we did in our generation, and they seem to get news, information and analysis in completely different ways than in the past, so there is a whole notion of information and media consumption that has undergone some pretty significant changes and probably will likely continue. The second aspect of that is kind of the business model of publishing information and publishing news and so on, and how that will continue to evolve in ways that perhaps are not necessarily clear at this point. And then the third aspect in terms of trends in business publishing, in the trends in publishing, is more of the operational dimensions and you know not to push the metaphor too far, but you know where the tail is wagging the dog, and so some minor portion of an overall media enterprise, because it is hot, it is trendy, it is most prominent, basically starts to drive the agenda. So, if you would, would you speak on any of those three things? Do you have this information consumption, the business model and operations?

KDW: Well, many of us are all saying the same thing these days, but, all things being open to 
interpretation, defining just what is 'news', particularly what the news is today and to not just one audience but many audiences in terms of what can be done with it from both the consumer and the provider sides, is so openended, an 'embarrassment of riches' so to speak, that, again, we really have to work to go beyond the day and age when the newspaper was delivered in the morning, you sat with it at certain times of the day, the only interaction with it was in folding it in certain ways to help read it and get what you need from it, and it reflected just the vision of the 'great white men' of a certain age. And we don't like to work. We want, but working to get what we want doesn't always seem to be part of the bigger cultural discourse these days, and, especially when discussing corporate culture. Now we're being technologically and culturally challenged in a way that many just didn't see coming - I certainly didn't when I was a 'kid' in the 80 s and 90 s - and, particularly, because 'seeing' is so often tied to experiencing.

MM: Funny, as a young adult in the 1970s some 85 per cent of adults watched the evening news.

KDW: Yes, well, so often and for fairly obvious reasons, the TV model, rather than the newspaper model, just seems to allow one an easier transition to the Web. But isn't that odd because did you ever think that you'd 'write' and 'publish' via a television monitor? One would think that the medium that would allow that would have been the more tangible and day-to-day writing one delivered on cheap, easily accessible paper - would have been the gateway. But it hasn't been the case. Then, when I think of what the news was, going back to a very young age, I don't remember 'wardrobe malfunctions' or the celebrity mania that we have now, but I do remember, even if I didn't know what it was at the time, the aftermath of the Vietnam conflict, Watergate, Walter Cronkite and so on. That was all from a time before I was really aware of the news, and I suppose I still have a kind of romantic notion of what news should be rather than what it is. It reminds me of the debate around 'Do you give them (the public) what they want or do you give them what they need?' I tend to fall on the side of giving them what they want because giving them what they need seems to be so arrogant; but then, today, even knowing what they want seems arrogant when reading so many articles and studies that say no one knows what they want. What they want is all whims to begin with!

And the even more romantic notion of curling up with the New York Times or whatever newspaper you prefer, maybe the London Times, and having 'special' or 'quality' time with it is so much a part of ways of coping with the modern world, even as it makes us more aware of the problems, troubles, issues of our modern world, that it does seem to hold us back technologically. Look at how long it's taken to come up with 'readers' that people will embrace in replacing the book or the newspaper, and consider the arrogance behind even thinking that something with the cultural legacy of the book or journal will just 'go away' because of some new innovation. I think we forget how long it took to get the book and the daily journal to the point that we know it to begin with, and something that takes so long to arrive doesn't just leave because we snap our fingers and say, 'Okay, now go, we have something better, and we THINK we can "monetize" it'.

As you suggested earlier, a whole generation has just never known other experiences, so they don't know what they want or don't want. None of us do; we're all limited by our realms of experience. It takes me back to Britannica. com, so, going back more than 10 years now a drop in a bucket time-wise - where I was really allowed the opportunity to explore online news subscriptions, Wikipedia, feeds, customizing them and all of that. I'm a bit ashamed to say that I stopped reading the newspaper then, though I'm consoled by being fully aware that I didn't stop reading the news, Obviously, I value 'the news', but I do find troubling the constant, sort of 'apples and oranges' comparison thinking that one way of acquiring the news will just automatically replace another. Strive as much as we want, I don't think the orange is in any danger of being replaced by the apple, and I don't think the interactive Web news experience is any threat to dinner-table conversations about newsworthy events. Each is a very different experience that has to be considered as such and scoped accordingly to succeed. Certainly, certain features of the older approaches translate to the 
newer ones, but that doesn't make the older ones disappear. Maybe word counts change; the established attributes, such as 'Headline', are augmented with newer attributes such as 'SEO Keyword'; the look of the articles changes and folds and creases are no longer evident though windows and pop ups are; font types and type colors change and so on. The real difference is that so many more of us have been invited 'to the table' - connect to the Web to get your dinner invitation - meaning so many more perspectives to take into account, so much more awareness of how the content is presented, delivered, and so much more awareness of the enormous number of decisions we have to make regarding what is and isn't important. Right or wrong, good or bad, invitations to valuable or 'the best' events still only go to the few.

MM: We go back to the grandfather of media studies, Marshall McLuhan, and the many ideas that he generated and injected into the conversation now going on 50 years. There is one particular thread that I really kind of want to pull forward into our conversation today. When you open a newspaper, a broadsheet, right, you are looking at almost a square yard of printed information and if you turn it upside down, so you are actually not reading anything and you look at the structure of what is on the broadsheet, you discover that there is a tremendous amount of energy and intelligence and work that goes into structuring that twopage broadsheet.

KDW: Yes.

MM: And in fact, when you open up a newspaper visually that you are immersed in this structure. You could almost call it a metamessage and basically it guides your eyes towards certain things, it creates a visual hierarchy, and with wide space and typography and design elements it really kind of breaks down a whole bunch of information into nice bite-sized chunks, and even when you are looking at an article and you see little subtitles or spikes in the columns and so on, it kind of draws you in, and for the most part that metamessage, that structural context of a broadsheet, disappears when you visit a website.

KDW: Yes, it does, but I think just to a point. It's still there, but now it gets so obscured by so many other elements activated by interaction and agents and so on that the foundational aspects become obscured. It's a bittersweet thing because, in order to generate revenue these days on the web, in order to stay alive, these obscuring devices are felt by many to be necessary. Time will tell. I love the way you stated this, Michael, because my immediate image was of children who are suddenly taking newspapers and building other things with them, making other things with them, creating hats from them, Christmas trees by cutting them up in certain ways and so on, all of which obscures or disguises the newspaper's original intent, and in no way replaces the hats or trees under real circumstances! It's a different way of 'immersing' or enveloping oneself in or relating to a newspaper or the news, but, in the end, it only diminishes the asset and is nothing more than deficient simulacra of other things.

MM: The point that I really kind of want to drill into here is that when you open up a New York Times for a two page spread or whatever, and you try to recreate that, basically we try to recreate that with site navigation and metadata.

KDW: Yes, right.

MM: So, in that context metadata has to work in the site structure, in the navigational structure, the tag clouds and other kinds of navigation aids, so I have to work doubly hard if not triply hard to recreate that panoramic vista.

KDW: Yes, and then make sure, after expending that hard work, that you don't undo it with confusing elements.

MM: That is inherent to the newspaper, but basically is flattened almost to the point of non-recognition on a little laptop, especially when most people are reading their newspaper on the laptop screen.

KDW: Well, with the trade news format of the newspaper, you know what to expect. With the interactive format, you don't necessarily know what to expect because board meetings, or financials or cults of personality shout, 'Change!' so often to stave off failure, obliteration or prop up partners, that throwing all ingredients into the soup just makes for a muddy, unappetizing soup. This wasn't the case with old-school newspapers: the technology, the behemoth printers and truck route delivery systems couldn't just be 'changed' as readily as interactive technology can be. In a way counterintuitive to how we like to think of ourselves, what we do and how success occurs, 
it was the slower approach - not to gathering the news but to disseminating it - that allowed us the ability to get to know and appreciate the product, learn its layout, scan it easily and so on. We just do not have that with all web experiences; with some, yes, but not with all. The interactive experience has to be thought of more in terms of what does require it, say, improved approaches to allowing end-users to search for content, rather than how more generally - more clicking, more scrolling, more rolling over, etc, just gets in the way. Though, come to think of it, remember how much the microfiche readers got in the way of research? There are always limitations. And, again, there really are no 'solutions' except for the Icaruses and builders of Towers of Babel among us, and I'd like to think that we, collectively, remembered what happened to them. Being able to say, 'Enough', or 'That'll do, pig, that'll do', is valuable.

MM: Well I think ... by the way I think that extra work translates into shorter sessions with the content. Shorter, you spend less time in the story when it is interactive.

KDW: Exactly. Then there is the whole business of 'working as expected' on all the devices, on my little iPhone, via my Mac Safari browser at home. All these more and different factors that come into play to the point where, sometimes, you don't know if the interactive experience is working for you or you're working for it. Is it leading you anywhere or providing anything useful to you? Utility does seem to be a thing of 'the old days'. Maybe that's what one loses with 'infotainment'. Remember how frustrating it was when reading the newspaper you found that a section was missing? You'd get to an article, there was the little end reference that told you to go to such and such a page, and when you couldn't get to that page you went crazy! So the newspaper approach was certainly not without its flaws. But, you also have to think: How often did that happen? Not very often, and then you knew that some human agency or easily identifiable machine issue was involved in the error: either the newsboy accidentally dropped the section or the printer 'hiccupped', and even that frequently had something to do with human agency or its lack. Some human agency is still involved, but, for some reason, we want to believe that the dumb machines will take care of it, that they are far smarter or developed than they really are, and human agency is a thing of the past. As a friend from my Britannica days said, 'It isn't called "artificial intelligence" for nothing!' and, like the artificial hat or tree made from a newspaper, it doesn't substitute ... yet ... for the real thing. Now, trying to account for or identify all the potential points of failure for just getting from one page to another seems out of control. Perhaps it's the inevitable, hysterical outcome of having so many at the table. Can you imagine what dinnertime was like at the immense Tower of Babel? It might have been McLuhan who referred to the point where something is as perfected as it can be, as much of a solution as it can be - and that could fall far short of what we demand - but it's just what it IS. From there, we start destroying it, undermining it, trivializing it, de-valuing it, and that is happening on an almost constant basis these days. Recently, I've read that much of this comes from a certain stumble the higher education system has taken in allowing too many in, always demanding new, competitive ways of describing the old or constants - new ways to describe the sun and everything that has always been under it - leading to a state of confusion. This then goes into the corporate fabric of a society, and, voila! You have economic chaos. I know that's a trivialization of a much more complex issue, and it smacks, weirdly, of a certain kind of elitism, but I'm beginning to think that there might be some truth to it, as uncomfortable as it makes me. It's as if we make our interactive experience, our applications, all of our hard work in preserving our assets, obsolete before we even get them into the hands of consumers and give them time to do something with them. I think it's always best to keep perspective and remember that, with so much of the technology now at our disposal - its 'space', its features, its possibilities a very short amount of time has elapsed while there is a majority interacting and working in it. MM: There is another theme here that I would like to kind of bring in with respect to this shift in publishing media consumption and the entailments in terms of business model and operations. In the mid-90s, my partners and I did a series of rather extensive research studies where we investigated software programmer 
productivity, their consumption of technical support services and information, and correlated those consumption behaviors with time to market, quality defects and calls for technical support, which entails a $\$ 225$ technical service cycle, and our sponsors asked us really to identify all the things that they provisioned or published that most directly led to increasing programmer productivity as measured by time to market for new products, product shipping with defects, and overall market acceptance of products that they sold and also on the back end in terms of how many calls for service did not show up as a function of not consuming these expensive technical resources. Here is what we found. We found that first and foremost the pixilation of information and knowledge, which is to say the delivery of it and the presentation of it to a screen, destroyed all long-term memory potential. Or another way of saying that is can you remember, can you recall with clarity and certainty, anything that you read on your computer screen 2 weeks ago and I am hard pressed to find a single individual who can, and then if I say 2 months ago out of a thousand people I have asked maybe there is one, right?

KDW: Right, right.

MM: So, essentially pixilation of information produces amnesia. It produces a deep stopper. KDW: Yes. Well, pixilation produces millions? Billions? Then, add 'more options' and 'more choices', 'fewer barriers', 'more invisibility', in other words, take away parameters and let the pixels loose, seemingly out of the confines of their container, and how do you account for them? How much can one person take in at a time, process, utilize and make valuable? Spread that over more and more people for more and more ... of what? We've lost or have yet to find, truly, a way to make the pixels valuable.

MM: And this clearly showed up in our benchmarking data and what we found was that pixelated information served a brilliant purpose of publishing what we call answers to right/ wrong questions. So if I needed to know something about how to turn this on or how to fix this thing or how to work around this thing, pixelated information as a function of its findability and retrievability worked brilliantly, but anything that went into long term, that you needed for long-term memory like knowledge structure know-hows ...

KDW: Right, right.

MM: So, that was done with computer programmers in the mid-90s, right. So, I do not know if the digital negatives or the medicines of today have developed compensatory skills for long-term memory retention. I suspect that they have, but I suspect that memory is starting to move from a solitary private world act to a shared public world process where if you are a kid today, you're 15 or 20 years old today, there are 5-10 people that you SMS 10, 20, 50 times a day.

KDW: Well, that refers back to spreading the pixels over more and more people and getting at 'the what' of just what the group wants or needs. Historically, that's not all that obvious. We look back at what has happened and make some predictions on what might happen under similar circumstances, factor in margins of error to account for disasters, wars and so on, but there is no real answer to what the group wants or needs. Anthropologists and sociologists know this, so they keep studying it knowing there is no one answer, but others don't get that. They want that 'one way' dogma on which to predicate business decision making.

MM: It seems to me that one of the things that some of the initial cognitive research and media psychology studies that I have seen indicates a transactional memory where individuals of a pod, because of their cognitive ability their particular intelligence specialty remember certain kinds, categories of information and experiences and makes them available to their pod almost on demand via SMS and instant message. So, from an immediate consumption perspective this has profound implications where now when we start publishing information, obviously one of the things we want to do is start to personalize this and individualize it, which means that we are really having to speak to cognitive specialties, but we also want to do that in a way that it is eminently sharable in the pod, so we really have two used cases or not used case contexts, first individualization to your particular cognitive specialties, and second optimization of it for sharing within a crew, a pod, a social community. 
KDW: But 'sharing' isn't really part of what we tend to think of as making for success. We talk so much about 'collaborative applications' these days; yet, collaboration doesn't come all that easily to people. So you have a space in which to share information - so what? You need a leader who can govern the space and make it useful. It goes back to the 'off the shelf' product: Plug it in, but don't expect it to do much unless you explore it, tell it what to do, govern it, emphasize its value and make it special. 'Pods', social communities, still need and will have leaders. They do rise up. Consensus will, too, and all the political things of the 'old school' will surface just as much with the new technology regardless of all 'empowering the individual' marketing spin put on the new applications.

This reminds me, again, of the notion that the machines somehow have within them, innately, the ability to know and do all, emulate and keep up with ever-changing human thinking or know exactly what a given end user - and I tend to think that, here, is where individualism comes into play because we're all individually 'looking' for some 'thing' that is unique at any given time, in any given place, and in relation to any number of needs and wants - really wants. I am always amazed by the persistence of thought that equates content management and search and retrieval systems with the scales that can tell you your weight and give you a 'fortune' at the same time. Like the old automaton 'fortune tellers'; and, we know how they worked: arbitrarily! This is in the face of knowing that, first, we have to describe our assets' metadata from a variety of perspectives or use cases in order to retrieve it and then do something with it. This is also in the face of knowing that measuring one's weight is a cross-referencing of a description of gravitational pull with a description of mass, and delivering a descriptive summary called weight. All of which isn't as easy or hokey as going up to a 'robot' dressed like a gypsy and taking from it a piece of paper that will make you feel better for the rest of the day because it says, 'You will come into a large fortune by year's end'. My own frustration with myself, and I suspect this is what feeds or creates so much organizational anomie, is that I can't get my hands on all the machines fast enough to develop them. Unfortunately, I don't have the luxury to believe in magic either.

MM: That really gets to the nature of information. In one sense, it is just red, green and blue dots - the rest of it you and I make up. Quite literally, we connect dots and experience it as information.

KDW: Yes, and once we make it, we have to keep some parameters on it and in mind to keep it from spiraling out of control and parameters keep it valuable. Otherwise, we just get overwhelmed and I am thinking of the young people to whom you referred. Either 'pod' or 'crew', we're talking about a relatively small group held tightly together.

MM: That is right. The sociologists are pretty clear that it is $4-8$ people and if it gets beyond eight people like an amoeba, it separates into two small groups that seem to be a real limit. What we are really talking about here, because ultimately we have to express this in metadata, and business rules rite?

KDW: Most definitely. We have to know where the 'tribe', 'pod' or 'crew' fits in the bigger 'civilized' system, but if we don't know, then we can't write the business rules that govern the machine. 'Anything Goes' is an old song from the 1920s. It is fun and people still sing it, but it doesn't do much for automation. MM: The machines mirror the reality of our social world, and a term that we have started to use here over the last couple of years in my work with some of these startups and social networking space, we call them trust spaces, is concentric rings of trust, and clearly beyond the living room or the bedroom as soon as we get out into a public space, we have a small group of people that are our best friend pods and that is $4,7,9$ people and then beyond that we have a crew which tends to be 9-15, max 20 people, and those are the people that are the next ring out, they are not your best friends, but they are good friends. And then as you start to move out beyond that you start to get into belonging to multiple tribes or what I call 'kenships', taking the old term ken or the group of individuals with whom you quite literally share a world view. Actually it translates as to see the world through the same set of eyes.

Funny, the Nobel Laureate Amartya Sen published a great book a few years back about the conflict of identity. He basically makes the 
case that we humans belong to multiple tribes. And that you have to have a multi-tribal model for a personality; otherwise you induce all sorts of needless conflict in our socialization, in our patterns of how we live, work and play.

KDW: I so appreciate the direction this conversation has taken, even though I know we're exchanging ideas at the moment under very controlled circumstances. That kind of control is part of our agreement, but that is exactly what is frequently lacking in so many enterprise organizations. For all the collaboration and need for interaction that we discuss, motivation frequently comes from rewards that insist on not collaborating, not being aware of the construct, and taking the 'anything goes as long as it puts me first' approach. But systems are integrated and they don't operate by incentives. Structure is ALL, and an attribute without a value is no good. Machines recognize but can't do much about infinite loops, though they can throw (out) exceptions.

MM: Cool. In the last issue, Carlos Gaviria talked about how XML has now begun to structure workflows-as-conversations in advertising agencies, marketing firms, publishing organizations. He made a deep connection in content creation with next-generation programming and software development techniques, specifically agile methodologies ... Where you have got small groups that are highly immersive and interactive at producing small chunks of code that they immediately text, that they build against stories and used cases, and what unifies it is a collaboration platform, certain technical standards, but more specifically kind of a web service, kind of a service-oriented architecture, web services, integration framework. So, we are seeing the same kind of thing and in fact we have begun talking about it in terms of agile content development, where we now see the application of agile development methodologies to the creation of content.

KDW: Your words 'interacting' and 'conversations' are keys for me. The amount of pressure applied to managers these days to take great numbers of people from so many cultural backgrounds, and effectively communicate with them to support the notion of agile or agility as we know it in a day-to-day sense, but then to apply it in a production realm, is enormous.
Again, it seems frequently counterproductive or 'just doing X' borrowed from one cultural environment because it supposedly 'worked successfully' there and then forcing it on a very different cultural environment. Why not look at what IS working in one's smaller environment or area of influence and control, plot out its parts, and then apply what is working more and more to the specific environment at large? Relatively, the smaller groups work together for the greater good when their successes are clearly communicated to them, and their approaches are replicated. Not to harp on the cultural studies drum too much, but this is all just kind of basic. It's amazing how much good communication, and not just any communication, particularly not desperate, anxiety-ridden communication, supposedly factors into 'success' even when we're also aware that we're talking about 'advertising agencies, marketing firms, publishing organizations' which, historically, seem to thrive on desperation and anxiety! And machines don't know desperation from non-desperation, anxiousness from calm, but, when desperate or anxious programmers make mistakes, the machines do 'know' when there's an infinite loop.

MM: This leads into the thing that we want to develop here and we gave it a kind of a working title of Content 3.0 and the emergence of the Semantic web and particularly how Semantic tagging will begin transforming dark content into brightly lit findable, searchable, mashable, reusable content that leads to all kinds of unique experiences and revenue opportunities. KDW: Yes, well, when I talk about the system that I manage and develop, its architecture, its linguistic base, knowledge representations and so on, I think one thing that we have a great deal of work to do is in defining just what is the basis of relevance to the masses and in terms of corporate or huge collections of texts - assets. We know that with relatively small, consistent bodies of content it is much easier to 'put' them into structures for ease of access and retrieval. But content coming in from multiple feeds and covering all domains of knowledge, as well as the unpredictable nature of things that will suddenly provide a 'news' opportunity, well, then you're talking about something entirely different. We describe a subset of the content as comprehensively and as orthogonally as possible, 
but, in the end, we're only ever talking about a subset lending itself to informing the knowledge representations, so they are always insufficient. To think that they will ever be sufficient, 'solutions' or even, as I once heard, '98 per cent accurate' (2 per cent short of 'God') is just arrogant. But we still have to engage in this work as humbling as it is. Overall, it's the work of developing synonym rings, taxonomy, logic/rule definitions and so on, moving to the big-picture prize, the ontology or specification of a conceptualization supporting the dream of seemingly 'intelligent' Web interaction experiences. We're really trying to chart out a domain, a domain of things, and then communicate 'up', 'out' or 'in', depending on one's orientation, what we, as human beings, 'know' to the Web in a way that it can understand or infer.

MM: See, one of the things that I would like to interject here is that my first exposure to ontology did not come from linguists; it came from Philosophy.

KDW: Well, I think so many people do. They come at it from that direction, because that is what we remembered learning in school when studying philosophy and metaphysics. Some say we shouldn't borrow terms from other disciplines in order to describe what we're doing, but, when we first start communicating some 'thing', a borrowing is frequently all we have at our disposal in order to make a connection or description. The prefix 'meta-', is important here in its 'surrounding' of both physics and data.

MM: They are neatly interwoven and interconnected, but the taxonomists throw a lot of the baby out with the bath water when they start talking about ontologies. And I think it really gets to the heart of usability, relevance and, to use another funny word, salience. And specifically in the domain of philosophy, my interpretation of ontology leads me to say that ontology is the study of the nature of being, how I am related to the world, how I am related to my subjective experience, how I am related to my history. In practical terms, when I walk into a store, I assume that the dairy case is going to be in the back, and the fresh vegetables are going to be to the left. So, in my mind and more specifically in my brainstem, an instinctual pattern matching function scans for threats to my survival and enhancements to my survival, including food, shelter, sex, etc - all basic patterns of survival and the domain of the limbic system. There exists an ontology, a natural order to the world and specifically the principle organizing this world is my survival first, and second things that cause or induce my survival, specifically resources.

KDW: Yes, and you know I thought of this recently because I went into my local grocery store not realizing it went through a remodeling and reorganization of products, and I couldn't find anything! I got so frustrated, I walked out, and I went to another grocery store because my understanding of a domain had been disrupted, and I found it too difficult to relearn in the short amount of time that I had. When we speak of ontology in computer science or information management, then, borrowing that concept from another discipline or not, we're talking about the process of accounting, describing knowledge of a domain and then conveying that knowledge to machines in order to serve us better.

MM: This really gets to - I believe represents the quintessence of useful information, if not fungible information - content that you sell now or as a promise in the form of subscription. Sorry ... and I believe ... and again this is the part that I want to kind of have our conversation around. I believe that ultimately information is meaningless without a source point of view, without that authorial voice, and a lot of what happens in institutional information is the authorial voice becomes so imperial, so homogenized, that people have difficulty connecting with it on a basic humanistic 6-year-old emotion logic storytelling level.

KDW: Well Michael ... I think excellent again ... it is great talking to you, just on the whole, and personal level, other than aside from this interview in a way because I think you sum it up so well, and it goes back again to relevance.

MM: Are you suggesting that relevance is the junior partner of the senior partner of salience, what gauges me as a human being in a conversation?

KDW: Relevance and priority. We only have so many resources at our disposal, so many hours in a day, so we have to work with the 
germane and even with the ordering of the germane. We can't turn all and everything, overnight, into knowledge representations, rules that systems understand. Relevancy is the very slippery slope so obviously tied to relativity and only an egomaniac thinks that what is relevant to him is relevant to all - yet we know there is a base of understanding we share within the world in which we function, whether that's a tribe, a pod, a crew, something bigger or something smaller. So the work becomes focusing on that base, describing it, all the while knowing that, from someone's perspective somewhere, there are going to be gaps.

MM: Yes. They live in aboriginal tribes in deep Amazons, you know, yes, of course, these people do not relate to our point of view.

KDW: (Laughs) That is right, exactly.

MM: And I did have them in the Sierra Madre of California who do not relate to our point of view.

KDW: Exactly, but they can relate to 'chair', which goes back, again, to philosophy. When you say get a 'chair' to even one of these 'types', we know what we are talking about as long as we have the basics of a specific language under control. If I say, get a 'chaise' or a 'stool', we might start getting into trouble, but depending on the use case and the systems at our disposal, we could associate those terms with 'chair' and provide utility. What we do then with what we develop, what we associate, is up to us. Maybe it is just helping us understand better what our content assets are really 'about' or the language used to describe the news in the day of very creative journalism. I remember last year wondering why the term 'Russian Literature' was being used to describe a sports article. When I read the article, I saw that the sports writer was comparing a modern-day game of some sort to Tolstoy's Anna Karenina. Why? I can't remember, but it says a great deal about the object of description and the descriptor. Then do we 'blame' the system for finding this? For pointing out that the sports article has a relationship to RusLit? Do we 'blame' the writer for being creative or broadthinking? Of course not, but we do KNOW more about the content than we could have gleaned just from the headline or section of the newspaper in which we think the content belongs. And if we think there's enough of a comparison between this game and Russian literature to warrant putting the article in the literary supplement, then we can re-use it for that too. At another point in time, many years ago perhaps, there may have been a very terse editorial dictum that said, 'No creativity. Do not make analogies between sports and Russian or any other kind of literature. Just report on sports'. But times have changed.

MM: When you think about a sports article in 1880 or 1890 and who was reading it ... How many of those readers had a college education. KDW: Exactly. The symbiotic relationships existing between the audience and the writer, the content and the automated indexer or tagger cannot be ignored.

MM: Yeah, and at that point America was still very much of, you know, an ocean-locked isolated native people that did not have a deep cultural residence, except as an immigrant with the old country.

KDW: Exactly - that is exactly the point, and now we have all of this content, all these channels, all this natural language processing of the output of all these paid writers - sometimes getting paid by the word - or not paid because they're bloggers. It's all out and happening on the Internet, and we call it that for good reason. MM: This is exactly the revolution that is underway and it stems from a conversation I had with a fellow named Amit Seth who was one of the vice presidents at Yahoo! that created their metadata model for advertising and user engagement. He said that at Yahoo! there are 2000 data facets to describe a Yahoo! visitor. And so there are 2000 discrete pieces of data that Yahoo! can ascribe or associate with each Yahoo! user and then correlate those facets, any number of those facets or sets of those facets to an advertising inventory as well as to a content inventory, and so it seems to be that we now see three sets of metadata, advertising inventory, brands, products, target markets, use cases, stories, narratives, content of metadata, which is content analysis, topic maps, themes and concepts in the article as well as user metadata, if you will the personal facets of this digital persona. It gets to the underlying business model of how do you orchestrate so that the user, so that the system, presents to the individual user, given these facets. The right chunks of data plus a tag cloud of other 
conceptually related content to not only just the article, but that particular use of profile consuming or engaging that article. And then as a function of that connection or the correlation between a user persona and the content as well as the associated tag cloud that is degenerated from that particular section you have a particular set of ad inventory dynamically served not to the user, not to the content, but to the user content profile, the relationship, what we are now targeting. So, then what we are targeting are not users, but relationships. Relationships between users and content in a particular section, and that represents kind of almost a fundamental paradigm shift in terms of targeting and search optimization.

KDW: As you were speaking, I was zeroing in on the number of systems you were talking about, and I think this is something that starts being very unclear and quite a challenge for broadly defined 'management', and especially for those managers coming out of more traditional ways of managing an enterprise. You used a very interesting word in there, Michael, that I appreciated: 'Orchestrated'. How do we orchestrate all of this? I thought immediately of an orchestra and a conductor, but the conductor is the one who is really keeping it together.

MM: That editorial, authorial voice.

KDW: Exactly. Now sometimes one thing that is very interesting about the conductor of an orchestra is how well ... you know you just do not put someone, say, the usher in a theater, in the role of the conductor; you put someone who really knows how to read music, compose music, knows the dynamics of how it should be played - not a virtuoso but close.

MM: Well, actually if they were a virtuoso, they probably make a crappy conductor.

KDW: Well, that could very well be, yes.

MM: I am just saying that in terms of that particular discipline, virtuosos make very crappy conductors.

KDW: Well, a virtuoso is going to be so in love with his instrument that he wouldn't want to conduct anyway. He's going to want to perform. MM: Exactly.

KDW: But, in the end, the conductor still has to know the music, the content, the asset.

MM: Fine. I am thinking you said something earlier too that made me think about the blurring and the next generation of just what is going to be required of a really cutting-edge progressive twenty-first century product manager or project manager and you might have to really be well versed in a number of programming languages, a number of forms of logic.

KDW: Analytic disciplines.

MM: Yes exactly, analytic disciplines, and that it just does not come down to well, well, you know this person over here has got an MBA, let us throw them in there, the degree, the kind of you know sometimes blanket things. Then let us go back to the original thread around ontology and throwing the baby out with a bath water. I am coming back to the conductor of the orchestra is not so much concerned with any one particular performance. Nor is he particularly interested in kind of how the woodwinds and the reeds are doing. I believe that the conductor is most focused on an aesthetic ideal.

And an experience of the work. And that you could say that what drives and animates the conductor is the fulfillment of that ideal, which is a wow experience. So you could say that the conductor is all about a wow experience, revealing some deep, profound, eternal truth that transports us out of our day-to-day world into this transcendental world. This world of imagination and vision and possibility, and ultimately the charter of all great artists is to pull us out of the mundane into this other world. KDW: Yes, right, and that is definitely what interactive is attempting: a 'wow experience' revealing content, surfacing knowledge, helping us collectively live better lives by tapping into or entering the World Brain, permanent encyclopedia of H.G. Wells. Imagine the possibilities.

MM: Exactly.

KDW: Yes, it is to take us to this other place, this place that is magical, that has got all these things going on that engage you and keep you diving in, going back to it and so on.

MM: And I remember as a kid, looking through life magazine and having that same transcendental experience of navigating the world that I then reinforced with a stamp collection. And so I had this collectable ... I had this collectable mindset of correlating the stamps with these other short iconographic 
histories right with the stuff that I was reading in this kind of magical realm. That is essentially I believe the essence of what will revitalize the publishing industry. What can we do, how can we orchestrate all this stuff, to bring people into this other world?

KDW: Well, I think we need conductors with the right experience. The MBA scenario that you described is like telling any orchestra conductor, 'Sure, you can play lead for a heavy metal band, too, it's all the same, and you'll make millions!' and, of course, some conductors could, but not all. The right 'smarts' has to be part of the mix. And sometimes it's necessary to get rid of the old orchestra only interested in playing Baroque pieces and bring in a new one seasoned and capable of playing the Baroque but also eager to take on new art music.

MM: Out with the obsolete?

KDW: Well, getting rid of it is too harsh in a lot of ways and could really undermine an organization's knowledge management efforts. Transition is softer but the process isn't easy even though it's all very easy to talk about. For the news, going from the newspaper to the interactive, it has been very hard. I remember something said at the 2009 Semantic Technologies Conference in San Jose: Going directly to the world of interactive news delivery without coming out of a newspaper tradition is just easier, and, obviously, that makes a lot of sense. Of course, they'll have other unique transitions to make, but from the hardcopy, print source to the Web isn't one of them. At the time, that was relieving to hear even if it doesn't change things.

MM: Let me introduce an anecdote from Eric Schmidt, the CEO of Google, in an interview by Charlie Rose in spring of 2006. Charlie starts with, 'Google my God what is next?' And Eric being the kind of techie, engineering kind of guys says, 'Well, in order to answer kind of what the next way of innovation and technology and wealth creation is in mega initial public offerings (IPOs), I have to talk about what has been, because largely what is next is a function of what has been', and he says now this is not quite right, but it is close enough. The 1980s, as it relates to innovation and technology in computers, was all about hardware, and out of the 80 s we got the microprocessor, we got the IBM PC, and we got great companies like EMC and Seagate and Mac Store and Apple and Compact and Hewlett Packard and Dell and so on. By the time we got out of the $80 \mathrm{~s}$, kind of the whole space of innovation had been used up. Now it is not to say there was not going to be another great hardware company, but there were not going to be whole crops of companies springing up. So the 1990s was all about software and brought us great companies, Microsoft, SAP and Oracle, and PeopleSoft and Seibel and so on, right? By the time we got out of the 90s, now the whole space of soft package software had been kind of occupied and all of the basic needs had been satisfied. The first 6 years was all about Internet infrastructure, IT infrastructure, and out of this we got Yahoo, eBay, Google, Amazon and so on. And he says, 'And then by the time, as of today, we are entering a new era.' He says, 'Now I cannot tell you with the same clarity of $20 / 20$ hindsight of what is going to be, but we are pretty clear about what a couple of facets of what is next', and as a footnote, he has written close to 5 billion dollars of cheques on this next principle. So this is not just some guy in the diner going on about, you know, what the future could be. This is the guy who is within his company quite literally creating the future, inventing the future, and he says, 'The next wave of innovation in wealth creation as it will involve small groups of people producing and consuming small chunks of information and as they produce and consume this information, it achieves a critical mass and goes global and large almost overnight.'

Borrowing the idea from retail distribution, I want to expand the idea of inventory turns to a digital sphere: information-knowledge turns. Central to both ideas - inventory turns in distribution and information-knowledge turns in digital content - is a real gem of an insight. The greater number of turns that you can achieve produces both more efficient operation and greater value.

So then Charlie asks, "Well, what is the secret of getting small groups of people to produce and consume small chunks of information such that they achieve critical mass?' Of course, Eric laughs and says, 'Well Charlie that is the 64 billion dollar question, and candidly, if I knew I would not be telling you; I would be writing more cheques!' 
KDW: Again, that is a way of saying that we have to go back to our roots in many ways, the smaller groups, and that isn't anything new; we humor so many with thinking that they are coming up with the new. Getting small groups of people to produce is tricky because it relies on people management finesse, intimately 'knowing' what you're managing, and being able to communicate outward a strong vision about taking some managed thing to another level of utility or creative thinking.

MM: But that is the answer, I believe, to the question that you posed; that it is not about the content - it is about the communication, interaction and collaborations in small groups that your content induces, supports and reinforces.

KDW: And the alluring model of the startup, the small company with no overhead, a few people, that makes millionaires of the few overnight, is one that has really been misappropriated by big organizations in some cases because you can't just go from being a monolith to a powerful but small, highly functional piece of flint 'by yesterday'. A multi-faceted, multi-vertical enterprise is not a startup no matter how much it tries to 'crack' the startup formula. Of course, downsizing, putting breaks on spending, reigning in certain initiatives can start to get it to that smaller group, but put the brakes on too fast and you have a really dangerous situation on your hands. Don't put them on at all, and deal with another dangerous situation.

MM: In that case, their very survival requires it. KDW: Yes. Getting back to tribes, pods and crews doesn't really fit into what we think of as being traditionally successful; after all, an empire isn't a tribe. But it does so often seem that, in the interactive realm, less can very well be more. Cutting the Gordian knot into smaller pieces is sometimes the only way to get back to a more manageable experience.

MM: Well Alexander solved that, you know, 2500 years ago.

KDW: Yes, right. He took that sword and, whack, went right to it. But Alexander was a real force to be reckoned with, and he could take in a high-level view of it - decide where to cut it without much fallout. Corporate managers don't have that luxury, and sometimes their cuts are very damaging, particularly when it comes to losing corporate knowledge. You don't want to be hasty or inaccurate and wind up cutting what, with a change of management approach or style, could be a real asset.

MM: Okay, this brings me to a conversation I had with the Nstein user conference about asset repositories, content optimization, personalized websites, etc. I framed the business problem for publishing industry as, 'Gosh I can see many possibilities, I can see and envision what those would look like in our business, but we lack the operational capability to make the necessary changes. We just do not have the systems, processes and accountabilities to get from where we are today to where we need to be. How do we get there from here? Because we have ... you know we gotta publish every day, so it is not like we are sitting around with whiteboards in all of our walls and lots of coffee, you know, we got stuff to do!'

KDW: Yes, and automation means doing a lot more shit up front than those who just experience the result of it realize. The work done by 'the man behind the curtain' doesn't just happen by 'magic' even if he is called 'wizard'. Seeing the possibilities, too, comes from having the experiences, and not everyone has had the experiences that you and I have had. Back during my days at Britannica, I wish I had seen it then as I do now because I definitely would have taken better notes! But then that's hindsight for you.

MM: I do not think we will ever, or at least in my lifetime anyway, do that. What can we do to make that person incredibly productive?

KDW: I think we have to somehow remove a lot of the static surrounding just what is productive to begin with. From so many different directions, across industries, I hear a lot of the same thing: The result of information management activities for many just isn't valued or never satisfactory. I think continuing streams of negative messages - even just general, anecdotal messages like, 'We're drowning in information!' - certainly don't help. That's the static. Send a negative message out enough times and it will become reality. Then there is the notion that the people, those 'behind the curtain' or those developing the content, can somehow just be replaced by automation. Fears of that, and, again, the constant message that comes from many management quarters truly believing that more automation means fewer people (fewer 
salaries, lower health insurance costs), when I think we're seeing quite clearly that automation can really only do so much. Sure, you might be able to replace some salaries, some health-care benefits, but you're still investing in applications, upgrades, lisense agreements and help desks.

Then, in terms of productivity, I think of so many projects I've worked on which, at the project onset, post-project time was set aside for 'de-briefing' and 'review of lessons learned' to avoid making certain mistakes that slowed down productivity, yada yada. But then, at the end of the project, either that meeting didn't or couldn't happen because the next project had to get underway. Then there are the times that, when the meeting did happen, many times the thing that got in the way of the productivity in the first place was just something that, for 'political' reasons, couldn't be changed. That's just people though, human failing, and it occurs in every aspect of life. Automation only 'knows' what its model, people, tells it, and that message can get very garbled in transfer. Spend good money licensing all the 'off the shelf' collaborative environments, 'solutions' and productivity drivers you want, but they can't stand up to being undermined if that's what we set out to do or our track record shows that we do.

MM: It seems to me that this last point that you have brought forward really focuses on the need for leadership first, and second a special kind of leadership which I will call innovation leadership, so leadership that is specially about, Hey we need you to become more relevant and more salient with our core customer and I have a vision as far as what that looks like and I need a team to use a Jim Collins Good to Great term, I need the right people on the bus who are going to figure out how to get there. But it seems to me that the thing that is most missing today in the publishing industry broadly declared or framed is a real understanding, a penetrating insight as to the role of information in this cultural comments and the role - the primacy - of a point of view that is inherently sharable but tribal. And you know it clearly ... I think one of the themes to develop woven through our conversation is that we have got a lot of people, a lot of executives, who have some pretty fixed mindsets as far as what is news, analysis and opinion, and increasingly that is out of step with where consumers live, work and play.

KDW: Yes, but knowing that, we can do something with it. One of the things that inspires me, particularly in my work with the Tribune, is that I know, from so many conversations, from so much information much playing out in news reports about the news industry itself - that there is value in what we do in publishing. It might get bogged down by human flaws, but you don't engage so many and at such cost for so long in things that are not culturally significant. I keep going back to the orchestra because it works so well. It is one thing for someone to be appointed conductor and another when the conductor says, 'I want to come within 98 per cent accuracy of communicating to the audience "the music of the spheres!"' That's obviously a goal, but, all things considered, is it a realistic one? If it's thought to be, thought to be possible, communicating just what the "music of the spheres' is in the first place is the challenge. It might be one thing to the first chair violinist but is that the same thing to the retired high school chorus leader in the 38th row? Or the bored kid forced to sit in the audience when he'd rather be with his crew and gaming? Suddenly, the goal runs up against reality, and someone has to be accountable somewhere along the line, but how can it be the violinist who played every note correctly? And when it comes to the machine, do you hold the metronome accountable for not working when you haven't wound it?

Working at the Tribune during a really difficult transition period has been an eyeopener, but opening one's eyes to see an everincreasingly orchestrated effort to improve itself on so many levels is inspiring. It's been another great learning opportunity for me, and I think I'm taking better notes these days, too.

MM: Well this is a great place to conclude I guess. KDW: I think so, yes. 